\title{
Evaluation of natural zeolite as a viscosity-modifying agent for cement-based grouts
}

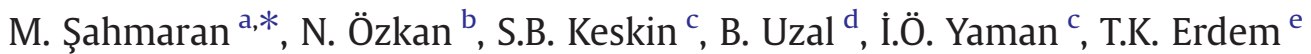 \\ a Department of Civil Engineering, Gaziantep University, Gaziantep, Turkey \\ b Central Laboratory RED-Training Center, Middle East Technical University, Ankara, Turkey \\ c Department of Civil Engineering, Middle East Technical University, Ankara, Turkey \\ d Department of Civil Engineering, Nigde University, Nigde, Turkey \\ e Department of Civil Engineering, Izmir Institute of Technology, Izmir, Turkey
}

\section{A R T I C L E I N F O}

\section{Article history:}

Received 9 May 2007

Accepted 12 March 2008

\section{Keywords:}

Grout

Rheological properties

Superplasticizer

Natural zeolite

Viscosity modifying admixture

\begin{abstract}
A B S T R A C T
The effects of natural zeolite on the rheological and workability properties of the grout mixtures were studied. Setting times of grouts were also determined as part of the experimental study. For comparison, grout mixtures were also prepared with a commercially available viscosity modifying admixture (VMA). The experimental results show that addition of natural zeolite modifies both the rheological and workability properties of grouts. For a constant superplasticizer (SP) content, an increase in the zeolite amount significantly increases the yield stress, the apparent and plastic viscosity, and reduces the fluidity and deformability. Moreover, an increase in the amount of SP causes a significant reduction in both the yield stress and plastic viscosity of the grouts. It was also observed that, grouts prepared with natural zeolite addition have a pseudo-plastic behavior, and shear-thinning behavior increases with an increase in the zeolite amount. Therefore, it has been shown that using natural zeolite as a VMA it is possible to obtain grouts that have satisfactory rheological properties, especially if natural zeolite is used in combination with a superplasticizer.
\end{abstract}

(c) 2008 Elsevier Ltd. All rights reserved.

\section{Introduction}

The pumpability and ability of grouts to penetrate voids and cracks are strongly dependent on their rheological properties. This is important in diverse grouting applications including ground treatment, repair of concrete, reduction of rock or soil permeability, environmental remediation, post-tensioning of concrete, rock anchors, sealing radioactive waste repositories, and well completion [1-6].

Chemical admixtures and mineral additives are often used to improve rheological, fresh, and durability properties of grouts. Chemical admixtures mainly affect the rheological properties of the cementbased grouts without altering the grouts composition. For example, grouts containing viscosity modifying admixtures (VMA) are used for filling post-tensioning ducts, where it is important to ensure high resistance to sedimentation and bleeding, hence ensuring corrosion protection of stressed tendons [1]. On the other hand, mineral additives affect both the rheological and hardened properties of grouts by altering its composition. Cement-based grouts with various mineral additives like bentonite, silica fume, fly ash, etc. have been used in modern practice for various grouting applications [2-6].

VMAs are relatively new chemical admixtures which are used to enhance the cohesion and stability of grouts [7-15]. Use of VMA increases the yield stress and plastic viscosity of cement-based grouts,

\footnotetext{
* Corresponding author. Tel.: +90 342317 2410; fax: +90 3423601107.

E-mail address: sahmaran@gantep.edu.tr (M. Sahmaran).
}

thus necessitating an increase in water/binder ratio or superplasticiser dosage to insure a low yield stress necessary for proper penetrability, spread, and controlled sedimentation. Cement-based mixtures containing VMA exhibit shear-thinning behavior whereby apparent viscosity decreases with an increase in shear rate $[7,8,13]$. Such mixtures (paste, grout, mortar or concrete) are typically thixotropic, where the viscosity buildup is accelerated due to the association and entanglement of polymer chains of the VMA at a low shear rate that can further inhibit flow and increase viscosity. Commonly used VMAs in cement-based materials include polysaccharides of microbial sources such as Welan Gum or starch sources, cellulose derivatives and acrylic-based polymers [7]. The mode of action of VMA generally depends on the type and concentration of the polymer in use. For example, Welan Gum increases the viscosity of mixing water since long-chain polymer molecules adhere to the periphery of water molecules, thus imbibing and fixing part of the mixing water. Molecules in adjacent polymer chains can also intertwine and develop attractive forces, thus further blocking the motion of free water and causing it to gel and display increased viscosity of the grout $[7,8]$.

One of the disadvantages of cement-based grouts with VMAs is the cost, associated with the use of chemical admixtures (such as superplasticizers) and use of high volumes of Portland cement in the production of grouts. One alternative to reduce the cost of cementbased grouts is the use of mineral additives such as limestone powder, natural pozzolans, slag and fly ash, which are finely divided materials added to the cement-based material as separate ingredients either 
Table 1

Properties of Portland cement and zeolite

\begin{tabular}{lll}
\hline Chemical analysis (\%) & Portland cement (PC) & Natural zeolite (Z) \\
\hline $\mathrm{CaO}$ & 61.94 & 1.85 \\
$\mathrm{SiO}_{2}$ & 18.08 & 69.75 \\
$\mathrm{Al}_{2} \mathrm{O}_{3}$ & 5.58 & 11.65 \\
$\mathrm{Fe}_{2} \mathrm{O}_{3}$ & 2.43 & 1.38 \\
$\mathrm{MgO}_{\mathrm{SO}}$ & 2.43 & 0.82 \\
$\mathrm{~K}_{2} \mathrm{O}$ & 2.93 & - \\
$\mathrm{Na}_{2} \mathrm{O}$ & 0.99 & 3.95 \\
Loss on ignition & 0.18 & 0.87 \\
& 4.40 & 8.90 \\
Physical properties & & \\
Specific gravity & & \\
Fineness (Blaine) $\left(\mathrm{cm}^{2} / \mathrm{g}\right)$ & 3.09 & 2.19 \\
Water requirement $(\%)$ & 3030 & 8210 \\
\hline
\end{tabular}

before or during mixing [16]. It is also known that some mineral additives, such as fly ash, may increase not only the workability but also the durability and long-term properties of grout [15]. Therefore, use of mineral additives in grouts will not only decrease the cost but also increase the workability and the long-term performance thus leading to a tri-fold benefit.

Zeolites are crystalline aluminosilicates having a three-dimensional skeletal structure based on repeated units of $\mathrm{SiO}_{4}$ and $\mathrm{AlO}_{4}$ tetrahedra [17]. Zeolitic tuffs are widely available in all over the world, which are present in low, medium, or high grade. They have unique characteristics such as high specific surface area and cation exchange capacity as well as ability to store heat between hydration and dehydration cycles [18]. Owing to their attractive characteristics, natural and artificial zeolites are utilized in several industrial applications. In building industry, although zeolitic tuffs have been utilized mostly as dimension stone, recently they have used as lightweight aggregates and mineral additives for blended cements or concrete $[18,19]$. Finely ground natural zeolite contains large quantities of reactive $\mathrm{SiO}_{2}$ and $\mathrm{Al}_{2} \mathrm{O}_{3}$ [20]. Similar to other pozzolanic materials such as silica fume and fly ash, zeolite substitution can improve the strength of concrete by the pozzolanic reaction with $\mathrm{Ca}(\mathrm{OH})_{2}$. In general, natural zeolite, like other pozzolanic materials, contributes to the strength of concrete better than the strength of cement [19]. Natural zeolite also prevents the undesirable expansion due to alkaliaggregate reaction and sulfate attack [21]. Moreover, zeolite, which is a softer material than the Portland cement clinker, increases the fineness of the ground material and reduces the grinding time [19].

However, to the best knowledge of the authors, there is no systematic study about the rheological properties of grouts containing natural zeolites. Hence, it is important to quantify the effects of natural zeolite on the grout behavior. Rather, careful consideration should be given to the design of grout mixtures containing natural zeolite, and its effect should be experimentally verified prior to use in field application. For this reason, the main objective of this article is to assess the potential usage of natural zeolite in grouts and evaluate its effects on the rheological properties of grouts. A total of 12 grout mixtures were prepared by adding various amounts of natural zeolite ranging from 20 to 40 wt.\% (by total weight of cementitious materials) at a constant water-cementitious material ratio $(\mathrm{w} / \mathrm{cm})$ of 0.60 . For comparison, grouts made with various amounts of VMA (without natural zeolite) were also prepared. The mini-slump flow diameter, modified-marsh cone flow time, setting time, and a coaxial rotating cylinder rheometer were used for testing the fresh properties of grouts.

\section{Experimental procedure}

\subsection{Materials and mixture proportions}

A CEM I-42.5R Portland cement (PC) complying with European Standards EN 197 (similar to ASTM C150 Type-I cement) was used.
Natural zeolite (Z) was used as a mineral additive. The natural zeolite was obtained in $0.6-1.2 \mathrm{~mm}$ sieved sizes and then ground to mineral additive fineness using a laboratory-type grinding mill. After 55 min of grinding with $70 \mathrm{~kg}$ steel cylinders, $8 \mathrm{~kg}$ material was brought to a fineness of $8210 \mathrm{~cm}^{2} / \mathrm{g}$ as measured with Blaine apparatus. Chemical composition and physical properties of Portland cement and natural zeolite are presented in Table 1. The particle size distributions of these materials, which were obtained using a laser scattering technique, are given in Fig. 1.

A polycarboxylic-ether type superplasticiser (SP) with a specific gravity of $1.08, \mathrm{pH}$ of 5.7 , and a solid content of $40 \%$ was used in all grout mixtures. The viscosity modifying admixture was the Welan Gum that is a high molecular weight microbial polysaccharide. The Welan Gum was supplied as a powder gum.

\subsection{Mixture proportions and test procedures}

As $w / \mathrm{cm}$ is a primary factor that would influence the fresh as well as the hardened properties of a cementitious mixture, to observe the effects of zeolite addition on a grout mixture $\mathrm{w} / \mathrm{cm}$ needs to be kept constant. Therefore, initially a number of trial grout mixtures varying in $\mathrm{w} / \mathrm{cm}$ are proportioned and cast to meet a sufficient fluidity and penetrability without segregation and bleeding. Fresh properties of each grout mixtures are then determined. From these trial mixtures, it was found that for the grout mixtures $\mathrm{w} / \mathrm{cm}$ should be higher than 0.50 to have sufficient fluidity and penetrability and less than 0.80 to have no bleeding and segregation. As a result, a w/cm of 0.60 is selected as an optimum ratio to produce a flowable and a stable grout without sedimentation and bleeding.

In order to investigate the effect of natural zeolite and its proportion on the rheological properties of grouts, twelve grout mixtures at a constant $\mathrm{w} / \mathrm{cm}$ of 0.60 are designed (Table 2 ). The variable parameters in these mixtures were the zeolite and SP amount. The grout mixtures had a zeolite amount of 20,30 and $40 \%$ and a SP amount of $0.25,0.50$, 0.75 and $1.00 \%$ (maximum limit recommended by the manufacturer) by weight of total cementitious material. One grout mixture (control sample) without any chemical and mineral additives was also produced for control purposes. In addition, similar grouts were also prepared with Welan Gum as a comparative test series. VMA content of $0.05,0.10$ and $0.15 \%$ by weight of cementitious material were used in these series. As shown in Table 2, the grout mixtures are labeled such that the ingredients are identifiable from their IDs. For example, the mixture Z30-S050 contained 30\% replacement of zeolite and 0.50\% SP and; the mixture V015-S100 contained 0.15\% VMA and 1.00\% SP.

The same mixing process was used for all of the grouts. The grouts were manufactured employing a standard rotary type laboratory mixer with the following standard procedure: the chemical admixtures (SP-VMA) were mixed with water for one minute and then the cementitious materials were gradually introduced in a minute. The grout was mixed at low speed (150 rpm) for 2 min, left to rest for $30 \mathrm{~s}$, and then mixed at high speed ( $240 \mathrm{rpm})$ for an additional four minutes.

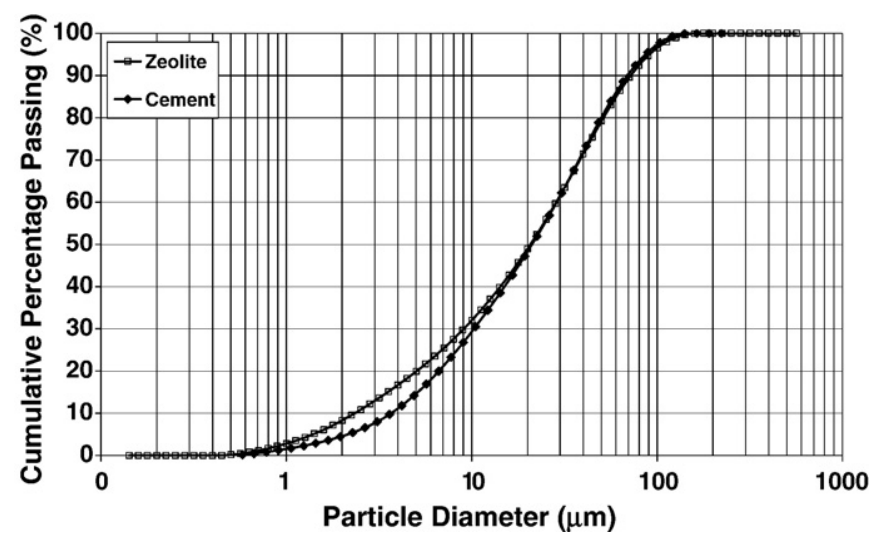

Fig. 1. Particle size distributions of Portland cement and zeolite. 
Table 2

Fresh properties of the grout mixtures

\begin{tabular}{|c|c|c|c|c|c|c|c|}
\hline Mix ID & $D_{\text {flow }}{ }^{*}(\mathrm{~mm})$ & $T_{\text {flow }}{ }^{* *}(\mathrm{~s})$ & $T_{\mathrm{f}, \mathrm{set}}{ }^{* * *}(\mathrm{~min})$ & Mix ID & $D_{\text {flow }}(\mathrm{mm})$ & $T_{\text {flow }}(\mathrm{s})$ & $T_{\mathrm{f}, \text { set }}(\min )$ \\
\hline Control & 145 & 13.70 & 548 & Control & 145 & 13.70 & 548 \\
\hline Z20-S025 & 99 & 20.76 & 510 & V05-S025 & 129 & 16.41 & 588 \\
\hline Z20-S050 & 126 & 16.66 & 517 & V05-S050 & 145 & 14.73 & 682 \\
\hline Z20-S075 & 128 & 15.26 & 523 & V05-S075 & 160 & 13.25 & 738 \\
\hline Z20-S100 & 135 & 14.93 & 536 & V05-S100 & 168 & 13.34 & 797 \\
\hline Z30-S025 & 71 & 59.29 & 491 & V010-S025 & 112 & 20.31 & 634 \\
\hline Z30-S050 & 80 & 53.18 & 503 & V010-S050 & 137 & 17.35 & 704 \\
\hline Z30-S075 & 91 & 26.42 & 512 & V010-S075 & 149 & 16.15 & 792 \\
\hline Z30-S100 & 109 & 18.50 & 520 & V010-S100 & 157 & 14.81 & 806 \\
\hline Z40-S025 & 68 & 66.35 & 478 & V015-S025 & 108 & 23.10 & 666 \\
\hline Z40-S050 & 70 & 62.83 & 480 & V015-S050 & 131 & 18.05 & 768 \\
\hline Z40-S075 & 75 & 35.49 & 490 & V015-S075 & 132 & 18.02 & 807 \\
\hline Z40-S100 & 85 & 20.17 & 494 & V015-S100 & 141 & 16.49 & 821 \\
\hline
\end{tabular}

* Mini-slump flow diameter

** Marsh-cone flow time.

*** Final setting time.

After the mixing was completed, tests were conducted on the fresh grouts to determine mini-slump flow diameter, marsh cone flow time, and setting time. Rheological measurements of all grout mixtures were carried out by using a coaxial rotating cylinder rheometer (Ares, TA Instruments, USA). All tests were repeated twice with a new batch of cement grouts and the results indicate that the tests were repetitive.

Workability (deformability and fluidity) of fresh grout mixtures were evaluated through the measurement of mini-slump flow diameter and modified-marsh cone flow time and all measurements were carried out at 7-10 min following the initial contact of cement with water. Both tests are easy to perform during field works to ensure the quality control of grouts. The mini-slump test is based on the measurement of the spread of grout placed into a cone-shaped mould. The dimensions of the mini-slump cone are proportional to that of the slump cone used for concrete (ASTM C-143) with a diameter of $38 \mathrm{~mm}$ at the bottom and $19 \mathrm{~mm}$ at the top and a height of $57 \mathrm{~mm}$ [22]. The modified-marsh cone test is based on measuring the time necessary for the flow of a particular volume of grout through a flow-cone. A plastic funnel with a capacity of $1500 \mathrm{ml}$ and an internal orifice diameter of $11 \mathrm{~mm}$ was used in this experimental study. The cone was completely filled with grout and the bottom outlet is opened, allowing the grout to flow out. Marsh cone flow time of grout was the elapsed time $(t)$ in seconds between the opening of the bottom outlet and the time for the flow of $1200 \mathrm{ml}$ of grout. The marsh cone flow time of fresh grout is compared to that of water, which was $9.7 \mathrm{~s}$. Moreover, the bleeding and sedimentation of fresh grout was measured following the procedure given in the ASTM C940-98. From this test, it was found that no stability problems in the form of segregation, bleeding or sedimentation were observed in any of the grout mixtures.

The apparent viscosity at different shear rates, plastic viscosity and yield stress of grouts were determined using a coaxial rotating cylinder rheometer. In coaxial cylinders, slip often occurs in the flow of grouts because of the depletion of the cement particles away from solid boundaries [23]. The yield stress measured using coaxial rheometers was largely independent of rotational speed, further suggesting the development of a slip layer [24]. In such a case, roughening the wall surface is desirable, but the extent of which depends to a great extent on the nature and size of the dispersed particles [23]. Slip effects can be enhanced by gravity for grout that shows any tendency to sediment with time [23]. In this study, the effect of slip was not considered. However, it is worth to note that all the grouts did not show any sedimentation during testing. For each grout mixture, the measurements were carried out by varying progressively the shear rate from 25 to $500 \mathrm{~s}^{-1}$. In order to evaluate the shear-thinning behavior of the grouts, the apparent viscosity of grouts as a function of the shear rate was also calculated. The flow curve was recorded for both the ascending and descending legs of the shear stress-shear rate curve. A typical flow curve of a grout mixture is plotted in Fig. 2. The top-curve (solid line in Fig. 2) corresponds to the undisturbed state of the grout where shear stress measurements were obtained by increasing the shear rate (ascending curve). The descending shear stress-shear rate curve (dashed line in Fig. 2) was obtained in a similar manner reflecting the rheological behavior of the grout following a given shear history. The experimental shear stresses considered in this investigation were taken from the ascending curve.

Various analytical models have been proposed to estimate the rheological parameters of cement-based grouts. Among these, the Bingham model $\left(\tau=\tau_{0}+\mu_{\mathrm{p}} \dot{\gamma}\right)$ is commonly accepted as representing the rheological behavior of cement-based grouts [25]. Yield stress $\left(\tau_{0}\right)$ and plastic viscosity $\left(\mu_{\mathrm{p}}\right)$ can be easily calculated from the flow curve (shear stress vs. shear rate). However, for highly pseudo-plastic grout mixture, the yield stress estimated by using the Bingham model is often higher than the true yield stress (Fig. 3). For this reason, in this experimental study the values of yield stress and plastic viscosity are obtained from the modified Bingham model (Fig. 3, second order polynomial equation), which is described by the following equation [25]:

$\tau=\tau_{0}+\mu_{\mathrm{p}} \dot{\gamma}+c \dot{\gamma}^{2}$

where $\tau=$ shear stress (Pa), $\tau_{0}=$ yield stress (Pa), $\mu_{\mathrm{p}}=$ plastic viscosity (Pa $\mathrm{s}), \dot{\gamma}=$ shear rate $\left(\mathrm{s}^{-1}\right)$ and $c=$ constant. The modified Bingham model ensures a better fit than the traditional Bingham model for the same data [8].

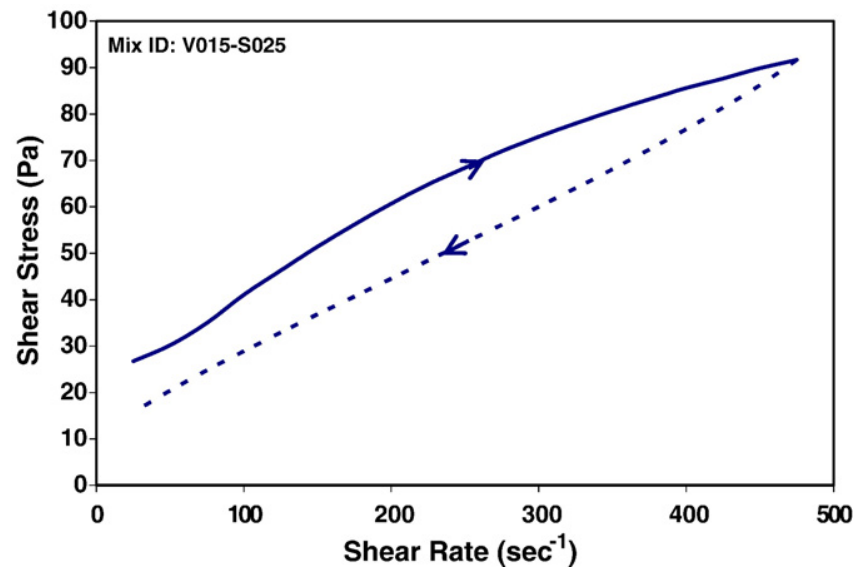

Fig. 2. Typical flow behavior of grouts obtained from the coaxial rheometer. 


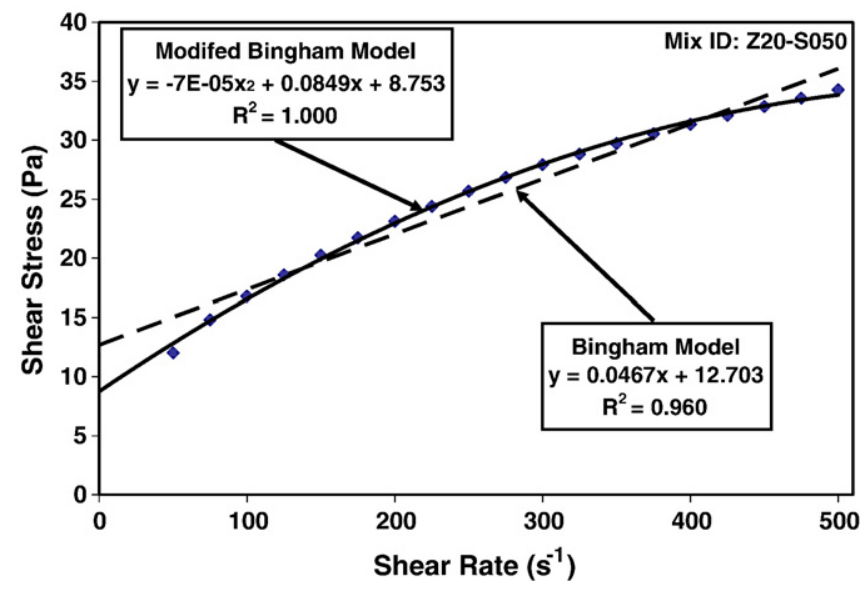

Fig. 3. Evaluation of rheological parameters according to the Bingham model and modified Bingham model.

The initial and final setting time of grout mixtures is evaluated by the Vicat needle apparatus. This test measures the penetration of a standardized needle in a sample of grout as a function of time (ASTM C-191). Initial setting time takes place when the penetration of the needle reaches $25 \mathrm{~mm}$. Final setting time corresponds to a zero penetration. Only the final setting time was considered during the discussion part of this study.

\section{Results and discussions}

Table 2 presents the workability properties (mini-slump flow diameter and marsh cone flow time) and final setting time of all grout mixtures. On the other hand, Table 3 presents the rheological properties expressed as the yield stress and plastic viscosity of all the grout mixtures. The coefficients of correlation $\left(R^{2}\right)$ of the modified Bingham model are also included in that table.

\subsection{Workability properties}

The workability properties (deformability and fluidity) of all grouts are summarized in Fig. 4. As seen from Fig. 4-a, regardless of the

Table 3

Rheological properties of the grout mixtures

\begin{tabular}{lrcl}
\hline Mix ID & $\tau_{0}(\mathrm{~Pa})$ & $\mu_{p}(\mathrm{~Pa} \mathrm{~s})$ & $R^{2}$ \\
\hline Control & 5.13 & 0.0299 & 0.994 \\
Z20-S025 & 12.78 & 0.1066 & 0.999 \\
Z20-S050 & 8.75 & 0.0849 & 1.000 \\
Z20-S075 & 7.29 & 0.0697 & 0.999 \\
Z20-S100 & 4.02 & 0.0461 & 1.000 \\
Z30-S025 & 15.51 & 0.1822 & 0.949 \\
Z30-S050 & 14.22 & 0.1292 & 0.985 \\
Z30-S075 & 13.14 & 0.1116 & 0.990 \\
Z30-S100 & 11.30 & 0.0795 & 0.996 \\
Z40-S025 & 18.78 & 0.2693 & 0.975 \\
Z40-S050 & 19.43 & 0.2382 & 0.967 \\
Z40-S075 & 17.51 & 0.2278 & 0.983 \\
Z40-S100 & 0.1721 & 0.993 \\
V05-S025 & 14.05 & 0.0924 & 0.991 \\
V05-S050 & 9.91 & 0.0911 & 1.000 \\
V05-S075 & 5.59 & 0.0820 & 1.000 \\
V05-S100 & 3.45 & 0.0834 & 1.000 \\
V010-S025 & 3.03 & 0.1551 & 1.000 \\
V010-S050 & 10.07 & 0.1442 & 1.000 \\
V010-S075 & 5.18 & 0.1373 & 1.000 \\
V010-S100 & 5.09 & 0.1143 & 1.000 \\
V015-S025 & 3.81 & 0.2511 & 1.000 \\
V015-S050 & 18.08 & 0.2359 & 1.000 \\
V015-S075 & 14.61 & 0.2690 & 0.999 \\
V015-S100 & 8.34 & 0.2163 & 1.000 \\
\hline & 6.42 & &
\end{tabular}

concentration of VMA, an increase in the SP content increases the mini-slump flow diameter and reduces the marsh cone flow time. On the other hand, for a given SP dosage, an increase in the VMA content slightly reduces the mini-slump flow diameter and increases the marsh cone flow time due to the water retention by VMA. When the grout mixtures with natural zeolite addition are examined (Fig. 4-b), it can be seen that the mixtures containing natural zeolite especially at low SP content $(\mathrm{SP} \leq 0.5 \%)$ showed less fluidity and deformability when compared with the grout mixtures made with various concentration of VMA. Moreover, increased amounts of natural zeolite significantly diminished the workability characteristics of the grout mixtures especially at lower SP contents. The reason of the reduction in the flowability and deformability of grout mixtures when cement is replaced with zeolite is attributed to the higher water retention capacity of natural zeolite. As seen from Table 1, the natural zeolite showed $18 \%$ increase in water content (water requirement of $118 \%$ as determined in accordance with ASTM C 311) to maintain the flow of fresh mortar when $20 \%$ (by mass) Portland cement is replaced by the zeolite. When the Blaine surface area of the zeolite and PC in Table 1 is compared, despite their similar particle size distributions as obtained from the laser scattering technique (Fig. 1), zeolite has significantly higher surface area $\left(8210 \mathrm{~cm}^{2} / \mathrm{g}\right)$ than PC $\left(3030 \mathrm{~cm}^{2} / \mathrm{g}\right)$. High surface area of zeolites results from the presence of a system of voids and channels in their crystal structure [17], which lead to adsorption of the more free mixing water. Another possible explanation is such that, a partial replacement of cement by natural zeolite at constant total weight of cementitious materials results in higher volume of paste due

\section{(a) VMA}

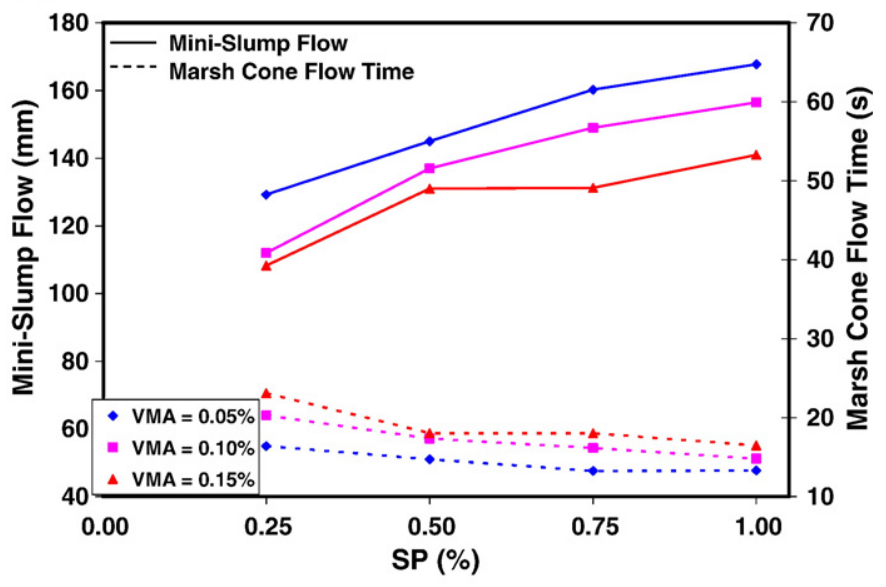

(b) Zeolite

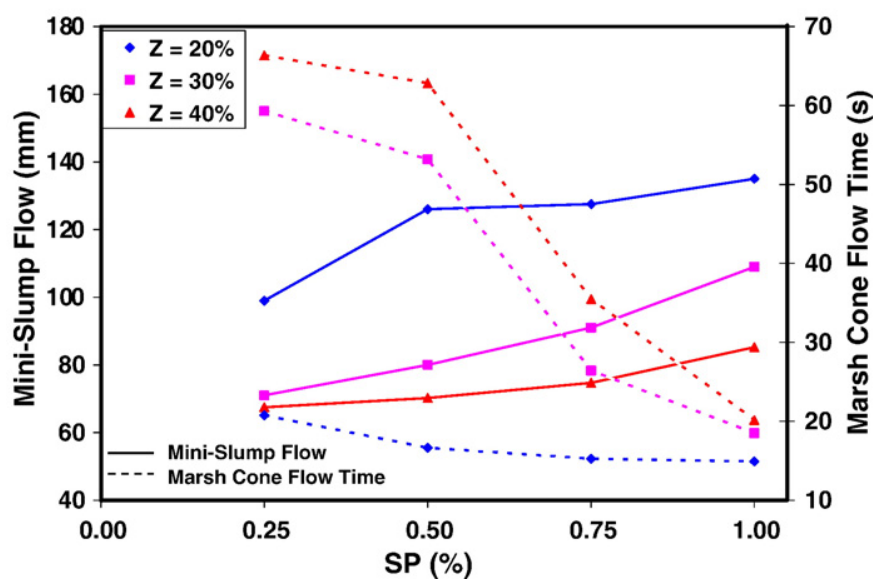

Fig. 4. Effect of VMA and zeolite content on the mini-slump flow and marsh cone flow time. 
to its lower density (see Table 1) and this increase in the paste volume (for a constant water content) increases the plasticity and cohesiveness, and thus leads to reduce workability, especially fluidity of grout $[16,26,27]$. Fortunately, as seen from Fig. 4-b, the increase in the dosage of SP in grouts containing zeolite significantly changes the deformability and fluidity of the grout. Therefore by adjusting the SP content in the grout mixtures made with the addition of zeolite, the deformability and fluidity properties can easily be optimized.

\subsection{Rheological properties}

The apparent viscosities of the grout mixtures at various shear rates are summarized in Table 4 for both the VMA and zeolite addition. Typical variation of apparent viscosities with shear rate for grouts with various VMA and zeolite content at constant SP content (1.00\%) is shown in Fig. 5-a. As seen from Table 4, the apparent viscosity decreases with an increase of shear rate for all the grout mixtures. As seen from Fig. 5-a, the higher reduction in the apparent viscosity of the grout mixtures containing VMA for a given range of shear rate indicates that the degree of pseudo-plasticity of grout increases with an increase in the amount of VMA. The increased pseudo-plasticity response in the presence of VMA is attributed to the entanglement and intertwining of VMA polymer chains at low shear rates and association of water between adjacent chains [7]. However, with an increase in shear rate, the entangled chains dislodge and align in the direction of the flow, thus decreasing the resistance of the grout to undergo deformation. The apparent viscosity is then decreased at higher shear rates.

Grout mixtures containing natural zeolite exhibit significant shearthinning behavior whereby apparent viscosity decreases with increasing shear rate (Fig. 5-b). Such mixtures are typically thixotropic where the viscosity buildup is accelerated at a low shear rate that can further inhibit flow and increase viscosity. For the same dosage of SP and at a lower shear stress, the use of natural zeolite on the order of $30-40 \%$ (by weight) results in a greater apparent viscosity than that of grout mixtures prepared with VMA on the order of $0.10-0.15 \%$ (by weight). As stated in Section 3.1, the addition of natural zeolite increases the water demand, and increased pseudo-plasticity response in the presence of natural zeolite may be due to the high water retention capacity of natural zeolite, which increases the agglomeration of particles. Grout is a concentrated suspension composed of cementitious material particles (cement+natural zeolite) suspended in water and mixing breaks down the flocculent structure responsible for thixotropic behavior of grout [28]. Thus, a highly thixotropic behavior grout mixture with natural zeolite is a result of combination of reversible coagulation, dispersion and then re-coagulation of the natural zeolite particles [29].

Another reason of increased pseudo-plasticity response in the presence of zeolite compared to similar mixtures without zeolite may also be attributed to the fact that zeolite could physically adsorb moisture owing to its high water adsorption capacity due to its large surface area and large number of micro-passages and cavities in the zeolite crystal structure [30]. Weakly bonded water in the structure of natural zeolite may not be released at lower shear stresses. However, with an increase in the shear rate, it might be possible that weakly bonded water will migrate from the structure of zeolite and increase the amount of free water in the system. Then, the apparent viscosity is significantly decreased for the grout mixtures with zeolite at higher shear rates. However, more experimental studies on a microstructural scale are necessary to clearly understand the mechanisms behind the increased pseudo-plasticity response in the presence of natural zeolite.

Yield stress is the stress above which the material starts to flow. Lower yield stress gives less resistance to start the flow and it is generally known that the slump property of a fresh cementitious mixture is mainly governed by its yield stress [31]. When the yield stress of a fresh cementitious mix is greater than the gravitational stress, the fresh mix is prevented from completely collapsing to the plate surface. Therefore, the penetrability of grout into voids or fissures will partially depend on the yield value.

Table 4

Apparent viscosities (Pa s) of grout mixtures at various shear rates

\begin{tabular}{|c|c|c|c|c|c|c|c|c|c|c|}
\hline \multirow[t]{2}{*}{ Mix ID } & \multicolumn{10}{|c|}{ Shear rate, $s^{-1}$} \\
\hline & 50 & 100 & 150 & 200 & 250 & 300 & 350 & 400 & 450 & 500 \\
\hline \multicolumn{11}{|c|}{ (a) Grout mixtures with VMA } \\
\hline Control & 0.121 & 0.081 & 0.063 & 0.053 & 0.046 & 0.041 & 0.038 & 0.035 & 0.033 & 0.032 \\
\hline V05-S025 & 0.310 & 0.172 & 0.145 & 0.129 & 0.111 & 0.098 & 0.089 & 0.080 & 0.074 & 0.068 \\
\hline V05-S050 & 0.219 & 0.146 & 0.126 & 0.114 & 0.105 & 0.098 & 0.093 & 0.087 & 0.082 & 0.077 \\
\hline V05-S075 & 0.157 & 0.112 & 0.099 & 0.092 & 0.087 & 0.084 & 0.081 & 0.078 & 0.075 & 0.073 \\
\hline V05-S100 & 0.148 & 0.110 & 0.097 & 0.091 & 0.087 & 0.084 & 0.080 & 0.077 & 0.074 & 0.072 \\
\hline V10-S025 & 0.362 & 0.242 & 0.207 & 0.186 & 0.170 & 0.157 & 0.146 & 0.137 & 0.129 & 0.123 \\
\hline V010-S050 & 0.249 & 0.186 & 0.165 & 0.154 & 0.145 & 0.136 & 0.129 & 0.123 & 0.118 & 0.113 \\
\hline V010-S075 & 0.213 & 0.167 & 0.151 & 0.142 & 0.135 & 0.128 & 0.123 & 0.118 & 0.113 & 0.108 \\
\hline V010-S100 & 0.223 & 0.161 & 0.141 & 0.131 & 0.124 & 0.120 & 0.115 & 0.111 & 0.107 & 0.104 \\
\hline V015-S025 & 0.604 & 0.411 & 0.343 & 0.303 & 0.274 & 0.250 & 0.231 & 0.214 & 0.200 & 0.187 \\
\hline V015-S050 & 0.519 & 0.362 & 0.311 & 0.280 & 0.255 & 0.236 & 0.221 & 0.207 & 0.196 & 0.186 \\
\hline V015-S075 & 0.382 & 0.309 & 0.282 & 0.262 & 0.243 & 0.225 & 0.210 & 0.198 & 0.186 & 0.177 \\
\hline V015-S100 & 0.362 & 0.286 & 0.254 & 0.231 & 0.214 & 0.201 & 0.189 & 0.179 & 0.171 & 0.163 \\
\hline \multicolumn{11}{|c|}{ (b) Grout mixtures with zeolite } \\
\hline Control & 0.121 & 0.081 & 0.063 & 0.053 & 0.046 & 0.041 & 0.038 & 0.035 & 0.033 & 0.032 \\
\hline Z20-S025 & 0.301 & 0.232 & 0.183 & 0.149 & 0.127 & 0.110 & 0.098 & 0.088 & 0.080 & 0.073 \\
\hline Z20-S050 & 0.240 & 0.168 & 0.135 & 0.116 & 0.103 & 0.093 & 0.085 & 0.078 & 0.073 & 0.069 \\
\hline Z20-S075 & 0.204 & 0.139 & 0.113 & 0.098 & 0.088 & 0.080 & 0.074 & 0.069 & 0.065 & 0.062 \\
\hline Z20-S100 & 0.127 & 0.084 & 0.071 & 0.063 & 0.058 & 0.055 & 0.052 & 0.050 & 0.048 & 0.047 \\
\hline Z30-S025 & 0.407 & 0.320 & 0.271 & 0.223 & 0.187 & 0.160 & 0.140 & 0.124 & 0.112 & 0.103 \\
\hline Z30-S050 & 0.353 & 0.269 & 0.211 & 0.176 & 0.152 & 0.134 & 0.120 & 0.109 & 0.099 & 0.092 \\
\hline Z30-S075 & 0.321 & 0.243 & 0.191 & 0.161 & 0.140 & 0.125 & 0.114 & 0.105 & 0.098 & 0.092 \\
\hline Z30-S100 & 0.277 & 0.192 & 0.151 & 0.127 & 0.112 & 0.101 & 0.093 & 0.086 & 0.081 & 0.077 \\
\hline Z40-S025 & 0.516 & 0.404 & 0.346 & 0.288 & 0.245 & 0.215 & 0.191 & 0.173 & 0.158 & 0.146 \\
\hline Z40-S050 & 0.526 & 0.397 & 0.337 & 0.281 & 0.236 & 0.204 & 0.179 & 0.160 & 0.145 & 0.133 \\
\hline Z40-S075 & 0.530 & 0.419 & 0.362 & 0.305 & 0.263 & 0.231 & 0.207 & 0.187 & 0.170 & 0.157 \\
\hline Z40-S100 & 0.392 & 0.306 & 0.254 & 0.217 & 0.191 & 0.173 & 0.158 & 0.147 & 0.138 & 0.130 \\
\hline
\end{tabular}


(a) VMA

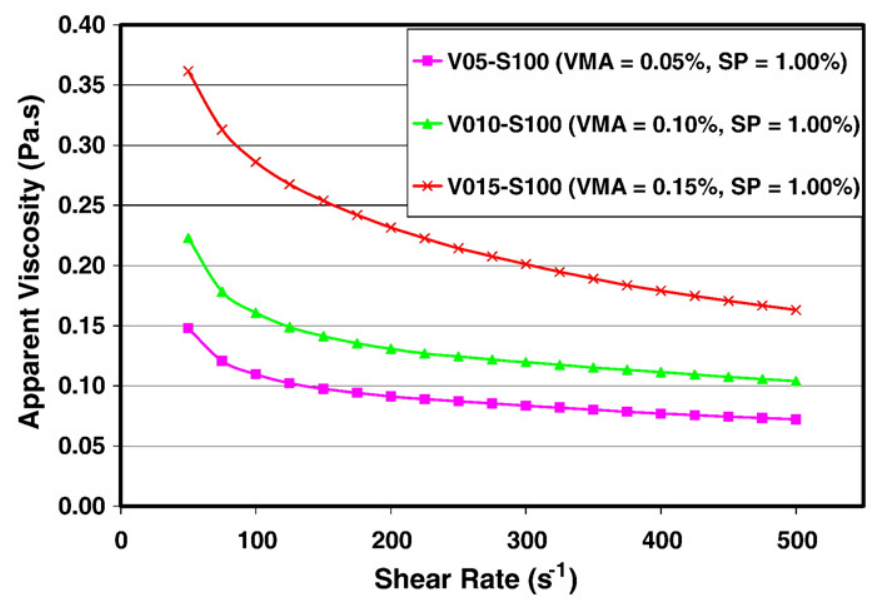

(b) Zeolite

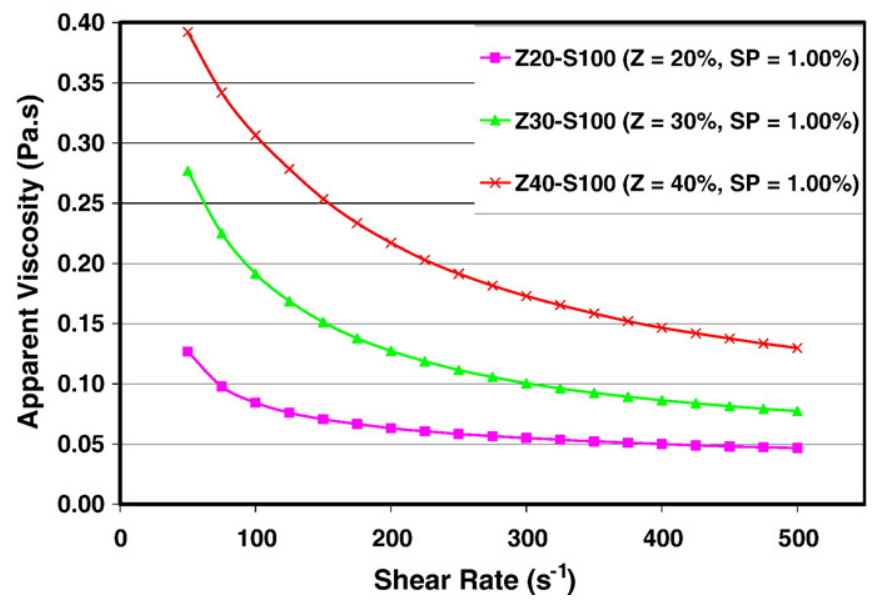

Fig. 5. Effect of VMA and zeolite content (at constant SP content) and shear rate on the apparent viscosity of grouts.

Fig. 6-a compares the yield stress of grouts with different amounts of VMA and natural zeolite. The yield stress is increased with the increase of dosages of VMA from $0.05 \%$ to $0.15 \%$. The yield stress is also affected by the combination of dosages of VMA and SP. As expected, at constant VMA content, the yield stress value decreases with increasing amounts of SP. It is then important to find out the proper combinations of dosages of VMA and SP to secure a stable paste with required fluidity and rheological properties. This can be achieved by testing trial mixes with various combinations of dosages of SP and VMA as illustrated in this study.

Grout mixtures with natural zeolite were also tested with different percentages of SP addition. The results for all grout mixtures with zeolite are presented in Fig. 6-b. Similar to the grout mixtures with VMA, yield stress was also raised by partial replacement with zeolite and this is due to increased surface area and flocculation. Both the yield stress and the shear stress at a given shear rate were increased with increasing zeolite addition (from 20 to $40 \%$ wt.). Fig. 6-b also shows that the addition of SP has a strong influence on the rheology of grout mixtures with zeolite even at a relatively high $\mathrm{w} / \mathrm{cm}$ of 0.60 . Thus, SP can be used to take the advantage of reducing yield stress where applications call for a high-fluidity grout.

Plastic viscosity is a measure of how easily the material will flow and it controls the spreading rate of a flow, once the yield stress is exceeded. In grouts, viscosity is a dominant factor to prevent segregation which is mainly caused by inhomogeneous flow between the ingredients of the fresh mix and gravitational sedimentation.
The effects of the amount of VMA, zeolite and SP on the plastic viscosity of grouts evaluated by the coaxial rheometer are shown in Fig. 7. As seen from Fig. 7-a, the plastic viscosity of grouts increases with increasing of VMA content regardless of the SP content. Therefore, for any given concentration of SP, the increase in VMA content increases the viscosity of grout. The addition of SP to the grout mixtures prepared with VMA has a slight effect on the plastic viscosity of those mixtures.

Similarly, the introduction of natural zeolite results in a significant increase in the plastic viscosity of grout. The comparison between the results of decrease in plastic viscosity with the addition of SP indicates that (Fig. 7-a and b) the addition of SP has a stronger influence on the plastic viscosity of grout mixtures prepared with zeolite even at a relatively high $\mathrm{w} / \mathrm{cm}$ of 0.60 . Therefore, greater concentrations of SP become necessary to reduce the plastic viscosity (or increase the fluidity) of grout mixtures especially at higher percentage of natural zeolite.

\subsection{Setting time}

The time required for grout mixture to achieve its initial and final sets is important, relative to its practical use in the field condition. In this part the final setting times are only discussed. Table 2 demonstrates the influence of chemical admixtures and natural zeolite on the final setting times of the grout mixtures. As seen from Table 2, the final setting time was found to be in the range of 478 and $821 \mathrm{~min}$. The final setting times of grouts got longer with an increase in VMA content. Similar observations were also made by other researchers $[7,8,32]$. The

\section{(a) VMA}

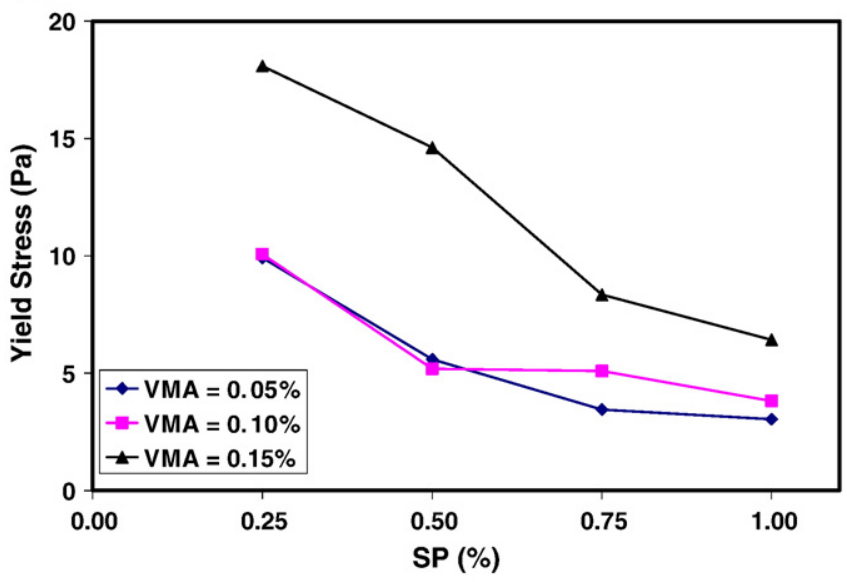

(b) Zeolite

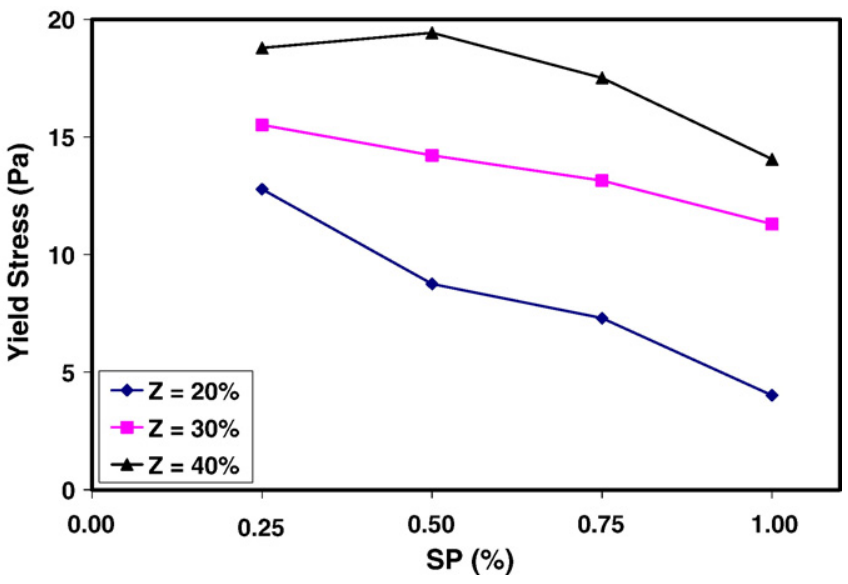

Fig. 6. Effect of VMA-SP and zeolite-SP content on the yield stress of grouts. 
(a) VMA

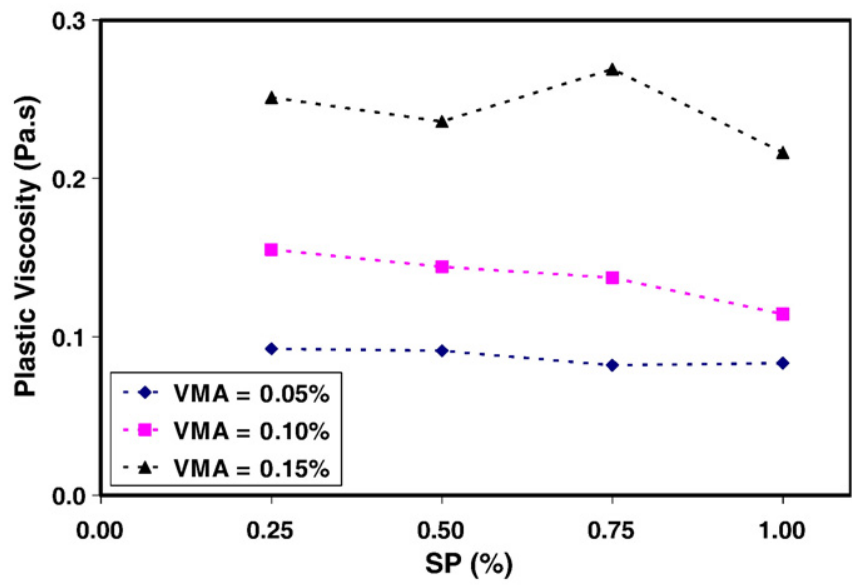

(b) Zeolite

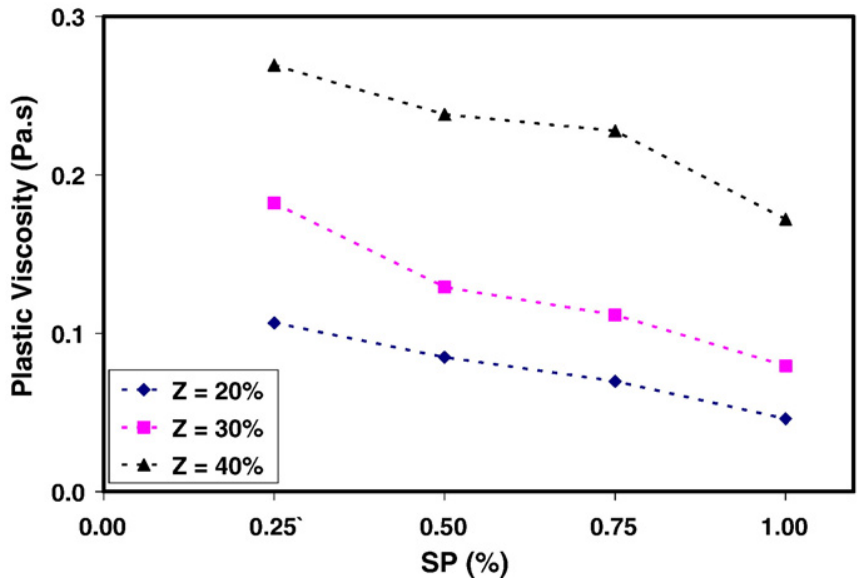

Fig. 7. Effect of VMA-SP and zeolite-SP content on the plastic viscosity of grouts.

reason of delay in the setting time when VMA is used in the production of grout can be attributed to the adsorption of VMA polymer chains onto cement grains and interfere with the precipitation of various minerals into solutions, which can cause a retarding effect on the rate of hydration and setting [8,32]. Moreover, the use of SP in combination with VMA significantly delayed the final setting times of grout mixtures. On the other hand, the use of natural zeolite in the production of grouts shortened the final setting time in comparison with the control mixture. The reason of reduction in the setting time of grout mixtures with natural zeolite may be attributed to the high surface area of natural zeolite particles, which lead to continuous adsorption of free water in mixtures after normal consistency condition satisfied at the beginning of the setting time measurements. Accordingly, shorter setting time values recorded for grout mixtures with natural zeolite are probably due to reduction in consistency of the mixtures rather than faster setting of the blended system. This kind of behavior, reduction in setting time, was already reported for natural pozzolan blended systems by others [16,33,34]. Moreover, increase in SP content slightly prolonged the setting times of grout mixtures made with zeolite. Set retarding is already a common behavior when SPs are added in cementitious systems.

\subsection{Correlation between rheological and workability properties of grout}

In order to provide simple and practical methods in standardizing rheological control of fresh grout, workability tests (mini-slump flow spread and marsh cone flow time) are correlated with the rheological parameters (plastic viscosity and yield stress). To identify any correlation between the rheological parameters and workability test results of grout, graphs were drawn between fresh test results of grouts and coefficients of correlation $\left(R^{2}\right)$ between any of the two fresh tests were calculated. An $R^{2}$ of 1.00 shows that the two test results are perfectly correlated. If there is no correlation or a weak correlation, the value of $R^{2}$ approaches zero.

The slump flow diameter is known to be an estimate of the deformability of concrete which is related to the yield stress [31]. For that reason, the yield stress of grout obtained from the modified Bingham model is also well correlated with the mini-slump flow deformation of grout as illustrated in Fig. 8-a. It can be observed from Fig. 8-a that the mini-slump flow of grout is found to increase with the decrease of the yield stress. The yield stress of the grout has shown good linear correlation with the mini-slump flow of grout, with $R^{2}=0.83$ (Fig. 8-a). Therefore, a quantitative indication of the yield stress could be obtained from the mini-slump flow deformation test. This result was expected because the grout in a mini-slump flow test will flow if the stress due to weight of the grout contained in the cone is higher than the yield stress of the grout [13]. Mini-slump test provides, however, no information on the plastic viscosity of the grout

In the marsh cone flow test, the grout starts to flow when the yield stress is exceeded, and therefore the measured value is highly related to the viscosity. Moreover, during the Marsh cone flow test, the grout is submitted to a higher shear rate than during the mini-slump flow test that can represent what happens during grout mixing and pumping in field works. From above, this relatively simple test method

\section{(a) yield stress vs. mini-slump flow}

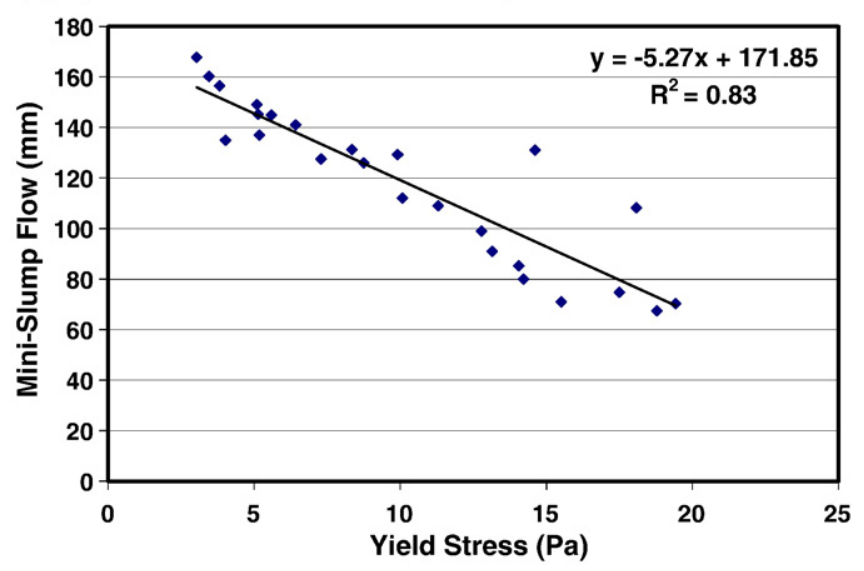

(b) plastic viscosity vs. marsh cone flow time

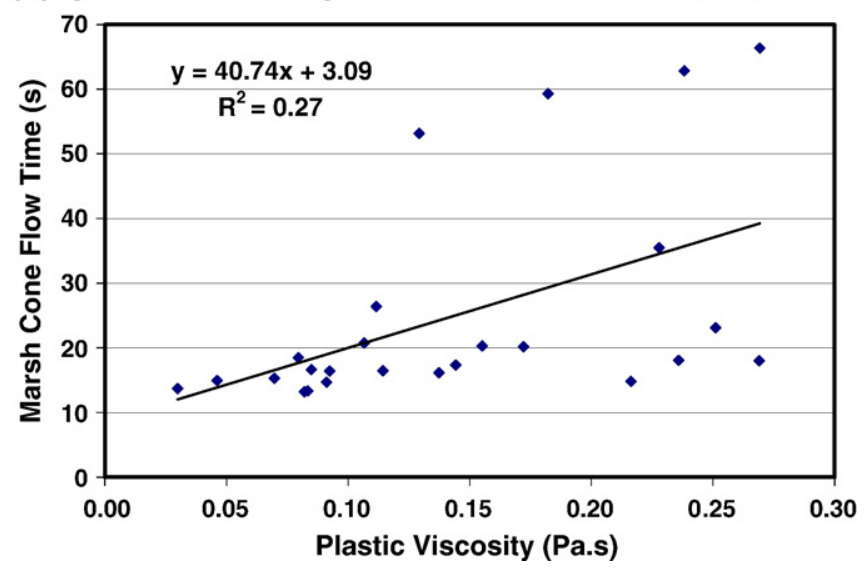

Fig. 8. Correlation between rheological and workability properties of grout. 
of marsh cone flow time may be expected to be used in field conditions in lieu of measuring plastic viscosity of grout. However, no correlation was observed between the marsh cone flow time and the plastic viscosity (see Fig. 8-b). Similar observations were also made by other researchers [35]. Therefore, in addition to viscosity, other factors such as friction can influence the flow of grouts [35]. Moreover, the flow time of $1200 \mathrm{ml}$ of grout from the marsh cone $(1500 \mathrm{ml})$ is difficult to measure, especially for the very flowable grout. Stopping the stopwatch when the $1200 \mathrm{ml}$ grout flows from the marsh cone is a subjective estimation and it is an even more difficult task for the highly workable mixes. This may be the other reason for the absence of correlation between the marsh cone flow time and the plastic viscosity.

\section{Conclusions}

The addition of both natural zeolite and VMA to grouts significantly modifies its rheological properties. The yield stress, plastic viscosity and apparent viscosity increases with increasing zeolite and VMA amounts. Grouts made with natural zeolite at $w / \mathrm{cm}$ of 0.60 show pseudo-plastic behavior, and shear thinning increases with the increase of zeolite dosage. SP can be used to decrease both yield stress and plastic viscosity of grouts. The addition of SP generally has a more significant influence on the rheology of the mixtures with natural zeolite when compared with VMA. Therefore, natural zeolite can be successfully used in grouts if combined with SP.

Both chemical admixtures (SP and VMA) adversely affect the setting time of grouts produced with only chemical admixtures. On the other hand the use of natural zeolite in the production of grout mixtures reduces the setting times. Moreover, the addition of SP in the grout mixtures prepared with natural zeolite does not influence the setting times.

Good correlation between yield stress and mini-slump flow deformation test has been established. However, no correlation has been observed between the plastic viscosity and the workability test results of grout mixtures.

\section{References}

[1] K.H. Khayat, A. Yahia, P. Duffy, High-performance cement grout for post-tensioning applications, ACI Mater. J. 96 (4) (1999) 471-477.

[2] P.C. Aitcin, G. Ballivy, R. Parizeau, The use of condensed silica fume in grouts, Innovative Cement Grouting, SP-83, American Concrete Institute, 1984, pp. 1-18.

[3] M. Bustamante, D. Gouvenot, Grouting: a method improving the bearing capacity of deep foundation, Eight International Conference on Soil Mechanics and Foundations, Helsinki, Finland, 1983, pp. 264-278.

[4] D.U. Deere, Cement-bentonite grouting for dams, Proceedings of ASCE Specialty Conference on Grouting in Geotechnical Engineering, New Orleans, U.S.A., 1982, pp. 279-300.

[5] J.G. Ruggiero, Low slump compactive tail shield grouting in soft ground shield driven tunnels, Innovative Cement Grouting, SP-83, American Concrete Institute, 1984, pp. 103-114.

[6] K.D. Weaver, J.C. Evans, S.E. Pancoski, Grout testing for a hazardous waste application, Concr. Int. 12 (7) (1990) 45-47.

[7] K.H. Khayat, Viscosity-enhancing admixtures for cement-based materials - an overview, Cem. Concr. Compos. 20 (2-3) (1998) 171-188.
[8] K.H. Khayat, A. Yahia, Effect of Welan Gum-high-range water reducer combinations on rheology of cement grout, ACI Mater. J. 94 (5) (1997) 365-372.

[9] V.A. Ghio, P.J.M. Monteiro, L.A. Demsetz, The rheology of fresh cement paste containing polysaccharide gums, Cem. Concr. Res. 24 (2) (1994) 243-249.

[10] V.A. Ghio, P.J.M. Monteiro, O.E. Gjørv, Effect of polysaccharide gums on fresh concrete properties, ACI Mater. J. 91 (6) (1995) 602-606.

[11] T. Kawai, Non-dispersible underwater concrete using polymers, marine concrete, International Congress on Polymers in Concrete, Brighton, UK, Chapter 11.5, 1987.

[12] T. Kawai, T. Okada, Effect of Superplasticizer and Viscosity-Increasing Admixture in Properties of Light-Weight Aggregate Concrete, SP-119, American Concrete Institute, 1989, pp. 583-604.

[13] M. Lachemi, K.M.A. Hossain, P.C. Nkinamubanzi, N. Bouzoubaâ, Performance of new viscosity modifying admixtures in enhancing the rheological properties of cement paste, Cem. Concr. Res. 34 (2) (2004) 185-193.

[14] M. Sonebi, Factorial design modelling of mix proportion parameters of underwater composite cement grouts, Cem. Concr. Res. 31 (11) (2001) 1553-1560.

[15] M. Sonebi, Experimental design to optimize high-volume of fly ash grout in the presence of Welan Gum and superplasticizer, Mat. Struct. 35 (250) (2002) 373-380.

[16] M. Sahmaran, H.A. Christianto, I.O. Yaman, The effect of chemical admixtures and mineral additives on the properties of self-compacting mortars, Cem. Concr. Compos. 28 (5) (2006) 432-440.

[17] G.V. Tsitsishvili, Natural Zeolites, E. Horwood, New York, 1992.

[18] C. Colella, M. Gennaro, R. Aiello, Use of zeolitic tuffs in the building industry, in: D.L. Bish, D.W. Ming (Eds.), Reviews in Mineralogy and Geochemistry, vol. 45, 2001.

[19] F. Canpolat, K. Yılmaz, M.M. Köse, M. Sümer, M.A. Yurdusev, Use of zeolite, coal bottom ash and fly ash as replacement materials in cement production, Cem. Concr. Res. 34 (5) (2004) 731-735.

[20] D.W. Breek, Zeolite Molecular Sieves: Structure, Chemistry and Use, Wiley, New York, 1974

[21] I. Janotka, L. Števula, Effect of bentonite and zeolite on durability of cement suspension under sulfate attack, ACI Mater. J. 96 (6) (1998) 710-715.

[22] D.L. Kantro, Influence of water reducing admixtures on properties of cement paste - a miniature slump test, Cem. Concr. Aggr. 2 (2) (1980) 95-102.

[23] H.A. Barnes, A review of the slip (wall depletion) of polymer solutions, emulsions and particle suspensions in viscometers; its cause, character, and cure, J. NonNewton. Fluid Mech. 56 (3) (1995) 221-251.

[24] A.W. Saak, H.M. Jennings, S.P. Shah, The influence of wall slip on yield stress and viscoelastic measurements of cement pastes, Cem. Concr. Res. 31 (2) (2001) 205-212.

[25] A. Yahia, K.H. Khayat, Analytical models for estimating yield stress of highperformance pseudoplastic grout, Cem. Concr. Res. 31 (5) (2001) 731-738.

[26] ACI Committee 232, Use of natural pozzolans in concrete, ACI Mater. J. 91 (4) (1994) 410-426.

[27] A. Yahia, M. Tanimura, Y. Shimoyama, Rheological properties of highly flowable mortar containing limestone filler-effect of powder content and w/c ratio, Cem. Concr. Res. 35 (3) (2005) 532-539.

[28] L.J. Struble, The rheology of fresh cement paste, in: S. Mindess (Ed.), Advances in Cementitious Materials, 1991, pp. 7-29.

[29] J. Wallevik, Rheology of Particle Suspensions, Department of Structural Engineering, The Norwegian University of Science and Technology, Trondheim, Norway, $2003397 \mathrm{pp}$.

[30] S.Y.N. Chan, X. Ji, Comparative study of the initial surface absorption and chloride diffusion of high performance zeolite, silica fume and PFA concretes, Cem. Concr. Compos. 21 (4) (1999) 293-300.

[31] C.F. Ferraris, F. de Larrard, Testing and Modeling of Fresh Concrete Rheology, National Institute of Standards and Technology, Gaithersburg, 1998 Internal Report 6094.

[32] M. Saric-Coric, K.H. Khayat, A. Tagnit-Hamou, Performance characteristics of cement grouts made with various combinations of high-range water reducer and cellulose-based viscosity modifier, Cem. Concr. Res. 33 (12) (2003) 1999-2008.

[33] B. Uzal, L. Turanli, Studies on blended cements containing a high volume of natural pozzolans, Cem. Concr. Res. 33 (11) (2003) 1777-1781.

[34] L. Turanlı, B. Uzal, F. Bektas, Effect of large amounts of natural pozzolan addition on properties of blended cements, Cem. Concr. Res. 35 (6) (2005) 1106-1111.

[35] C.F. Ferraris, K. Obla, R. Hill, The influence of mineral admixtures on the rheology of cement paste and concrete, Cem. Concr. Res. 31 (2) (2001) 245-255. 